PREPARED FOR THE U.S. DEPARTMENT OF ENERGY, UNDER CONTRACT DE-AC02-76-CHO-3073

PPPL-2873

PPPL-2873

UC-421

K $\beta$ SPECTRA OF HELIUMLIKE IRON FROM TFTR PLASMAS

BY

A.J. SMITH, M. BITTER, K.W. HILL, ET AL.

DECEMBER, 1992
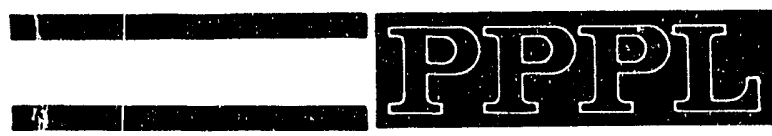

PAINCETON

plagma pMYsics

LABOAATOAY

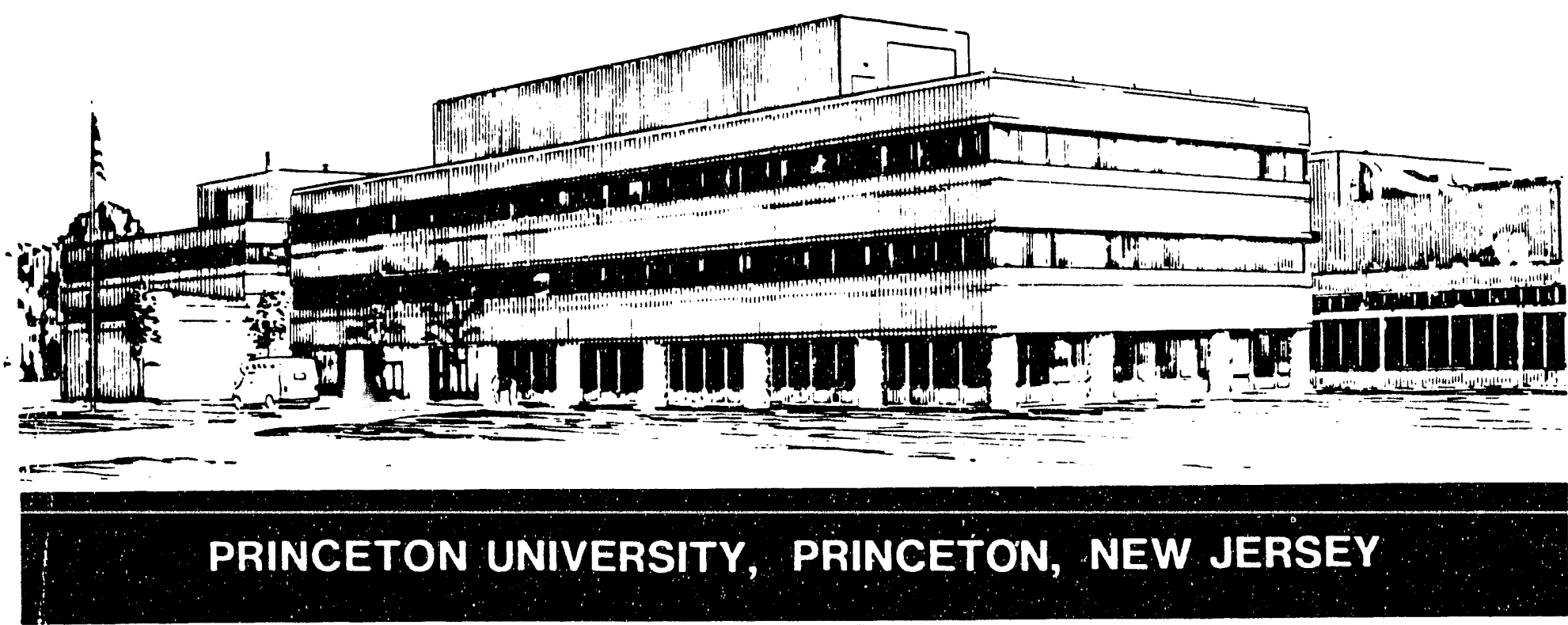




\section{NOTICE}

This report was prepared as an account of work sponsored by an agency of the United States Government. Neither the United States Government nor any agency thereof, nor any of their employees, makes any warranty, express or implied, or assumes any legal liability or responsibility for the accuracy, completeness, or usefulness of any information, apparatus, product, or process disclosed, or represents that its use would not infringe privately owned rights. Reference herein to any specific commercial produce, process, or service by trade name, trademark, manufacturer, or otherwise, does not necessarily constitute or imply its endorsement, recommendation, or favoring by the United States Government or any agency thereof. The views and opinions of authors expressed herein do not necessarily state or reflect those of the United States Government or any agency thereof.

\section{NOTICE}

This report has been reproduced from the best available copy.

Available in paper copy and microfiche.

Number of pages in this report: 25

DOE and DOE contractors can obtain copies of this report from:

Office of Scientific and Technical Information

P.O. Box 62

Oak Ridge, TN 37831 ;

(615) 576-8401.

This report is publicly available from the:

National Technical Information Service

Department of Commerce 5285 Port Royal Road

Springfield, Virginia 22161

(703) $487-4650$ 
PPRL--2873

DE93 005730

\title{
Kß Spectra of Heliumlike Iron from TFTR Plasmas
}

\author{
A. J. Smith
}

Lock Haven University, Lock Haven, Pa 17745

\begin{abstract}
M. Bitter, H. Hsuan, K. W. Hill, S. von Goeler, and J. Timberlake
Plasma Physics Laboratory, Princeton University, P.O. Box 451, Princeton New Jersey 08543

P. Beiersdorfer and A. Osterheld

Lawrence Livermore National Laboratory, Livermore, CA 94550
\end{abstract}

Muter 


\begin{abstract}
$\mathrm{K} \beta$ spectra of heliumlike iron, Fe XXV, have been observed from TFTR plasmas with a high-resolution crystal spectrometer. The wavelength range of the $\mathrm{Fe} \mathrm{K} \beta$ spectrum partially overlaps the spectrum of heliumlike nickel (Ni XXVII), which is used on TFTR and JET for ion temperature measurements. The experimental arrangement made it possible to observe the $\mathrm{Fe} X X V \mathrm{~K} \beta$ lines and their satellite transitions of the type $1 \mathrm{~s} 2 \mathrm{l}^{\prime} 3 \mathrm{l}^{\prime \prime}-->1 \mathrm{~s}^{2} 2 \mathrm{l}^{\prime}$, as well as the entire satellite spectrum of the Ni XXVII K $\alpha$ line simultaneously. In order to identify the features of the $K \beta$ spectra and to study their possible interference with the Ni XXVII spectrum, the intensity of the $\mathrm{K} \beta$ spectrum was enhanced by injection of iron into the plasma. Accurate wavelengths and intensities have been obtained and compared with different theoretical calculations.
\end{abstract}

*Supported by DOE Contract No. DE-AC02-76-CHO-3073 


\section{Introduction}

High resolution satellite spectra of high- $Z$ atoms are important for the diagnostics of tokamak plasmas and solar flares, and they are aiso of interest in testing atomic theories which must include relativistic and quantum electrodynamics effects. In the large tokamaks such as the Tokamak Fusion Test Reactor (TFTR), the Joint European Torus (JET), the large Japanese tokamak JT-60 U, and Tore Supra, where large volume $\left(>40 \mathrm{~m}^{3}\right.$ ) plasmas with peak electron temperatures $\sim 5 \mathrm{keV}$ are maintained for several seconds, hydrogenlike and heliumlike ions of high- $Z$ atoms such as titanium, chromium, iron, and nickel, are readily produced. Line radiation from these highly stripped ions is used for electron and ion temperature diagnostics as well as for determination of chargestate distributions and ion transport coefficients. In particular, the resonance line of heliumlike nickel ${ }^{1-4}$ is employed on TFTR, JET and Tore Supra for Doppler broadening and Doppler shift measurements in order to determine the central ion temperature as well as toroidal and poloidal plasma velocities.

In the case of TFTR and Tore Supra which use stainless steel ( 70 at. \% Fe, 20 at. \% $\mathrm{Cr}, \sim 7$ at. $\% \mathrm{Ni}$ ) walls and Inconel $(\sim 70$ at. $\% \mathrm{Ni}, \sim 15$ at. $\% \mathrm{Cr}, \sim 7$ at. $\% \mathrm{Fe}, \sim 2.5$ at. $\% \mathrm{Ti}$ ) bellows protective cover plates, iron and nickel are simultaneously present as wallderived impurities. Thus the possibility exists that the FeXXV $\mathrm{K} \beta$ spectrum and the NiXXVII $\mathrm{K} \alpha$ spectrum, which fall in the wavelength range from 1.57 to $1.62 \stackrel{\circ}{\AA}$, interfere with each other. It is therefore of considerable interest to determine whether a distortion of the Ni $\mathrm{K} \alpha$ spectrum by the $\mathrm{Fe} \mathrm{K} \beta$ spectrum impairs the ion temperature measurements. In this paper, we investigate the $\mathrm{K} \beta$ spectrum of heliumlike iron. Such a study is very important since experimental data on $K \beta$ spectra are scarce.

Under normal TFTR operating conditions prior to 1987 , when the present data were collected, the nickel $\mathrm{K} \alpha$ radiation was much more intense than the iron $\mathrm{K} \beta$ radiation. 5 Iron was therefore injected into the plasma by a laser blow-off technique in order to enhance the iron $\mathrm{K} \beta$ emission relative to the nickel $\mathrm{K} \alpha$ emission. Thus it was possible to extract the $\mathrm{Fe} \mathrm{K} \beta$ spectrum from the obtained composite spectrurn and to clearly identify most of the theoretically predicted features.

The experimental wavelengths of the $\mathrm{K} \beta$ lines and the associated satellite features were determined relative to the positions of nickel $\mathrm{K} \alpha$ lines with an accuracy of $\sim 0.1 \mathrm{~m} \AA$. 
An important result of our experiments is that the $\mathrm{K} \beta$ features are found to be well separated from the nickel $\mathrm{K} \alpha$ resonance line, so that there is no interference with the central ion temperature measurement. As an additional benefit, observation of the time history of the $\mathrm{K} \beta$ radiation following the iron injection makes it possible to study the confinement of metal impurity ions in TFTR plasmas.

The paper is organized as follows: Section II presents theoretical data on the iron $\mathrm{K} \beta$ satellite spectrum obtained from the Hebrew University-Lawrence Livermore Atomic Code (HULLAC) package. The experimental results and data analysis are described in Section III. Conclusions are given in Section IV.

\section{Theory}

The spectrum of interest includes the $\mathrm{K} \beta$ lines of heliumlike iron, corresponding to the transitions $1 s^{2}{ }^{1} S_{0}-1 s 3 p^{1} P_{1}$ and $1 s^{2}{ }^{1} S_{0}-1 s 3 p{ }^{3} P_{1}$, and the associated lithiumlike and berylliumlike satellites due to the transitions: $1 s^{2} 21-1 s 2 l^{\prime} 3 l^{\prime \prime}$ and $1 s^{2} 2 s 2 l^{\prime}-1 s 2 s 2 l^{\prime} 3 l^{\prime \prime}$. These satellites can be formed (1) in the process of dielectronic recombination of heliumlike or lithiumlike ions or (2) by collisional inner-shell excitation of lithiumlike and berylliumlike ions from their ground states. In the first process a free electron is captured by a heliumlike or lithiumlike ion into the $n=3$ level :

$$
1 \mathrm{~s}^{2}+\mathrm{e}^{-} \rightarrow 1 \mathrm{~s} 2 \mathrm{l}^{\prime} 3 \mathrm{l}^{\prime \prime}
$$

or

$$
1 s^{2} 2 s+e^{-} \rightarrow 1 s 2 s 2 l^{\prime} 3 l^{\prime \prime}
$$

The resulting autoionizing states given in Eq. (1) can decay by two types of radiative decay schemes :

$$
1 \mathrm{~s} 2 \mathrm{l}^{\prime} 3 \mathrm{l}^{\prime \prime} \rightarrow 1 \mathrm{~s}^{2} 31,
$$

or

$$
1 \mathrm{~s} 2 \mathrm{l}^{\prime} 31^{\prime \prime} \rightarrow 1 \mathrm{~s}^{2} 21
$$


The first type provides satellites to the heliumlike $\mathrm{K} \alpha$ resonance line. These, so-called unresolved $n=3$ satellites, lie very close to the $K \alpha$ resonance line and have been investigated rather well. 6 Of interest for the present paper are the transitions of the second type which give rise to $n=2$ satellites of the $K \beta$ lines. Because the plasma also contains lithiumlike ions, we expect to find satellite transitions from the dielectronic reccmbination of lithiumlike ions by radiative decay of the excited states given in Eq. (2):

$$
1 s^{2} 2 s+e^{-} \rightarrow 1 s 2 s 2 l^{\prime} 3 l^{\prime \prime} \rightarrow 1 s^{2} 2 s 2 l^{\prime}
$$

The relevant transitions due to the second process of direct electron-impact excitation of inner-shell electrons from lithiumlike and berylliumlike charge states involve only the ground states of these ions:

$$
1 s^{2} 2 s+e^{-} \rightarrow 1 s 2 s 31+e^{-}
$$

and

$$
1 s^{2} 2 s^{2}+e^{-} \rightarrow 1 s 2 s^{2} 31+e^{-}
$$

since the so-called zero-density limit applies to the low electron densities of TFTR plasmas.

In the following, we discuss the line emissivities for ions from different charge states. The emissivities of the heliumlike $\mathrm{K} \beta$ lines can be represented by

$$
\varepsilon_{H_{e}}=N_{e} N_{H_{e}} C
$$

where $N_{e}$ and $N_{H_{e}}$ are the electron and heliumlike ion densities and $\mathrm{C}$ is an effective excitation rate coefficient which takes into account direct excitation and radiative cascades. These rate coefficients were obtained with the HULLAC set of atomic codes, which calculate wave functions, energy levels, and radiative transition rates by the relativistic, multi-configuration parametric potential method with full configuration interaction. ${ }^{7}$ The collisional excitation rates were calculated in the distorted-wave approximation; an efficient technique, which performs an angular factorization of both the direct and exchange contributions to excitation cross sections and interpolates the necessary radial integrals as a function of threshold energy 8 was used. The excitation 
rate coefficients obtained from these calculations are given in Table I as a function of the electron temperature.

The emissivities of the so-called collisional satellites lines which result from inner-shell electron impact excitation of the lithiumlike and berylliumlike charge states are given by

$$
\varepsilon_{c s}=N_{e} N_{L(B e)} C \frac{A_{r}^{s}}{\sum_{f} A_{r}^{s f}+\sum_{i} A_{a}^{s i}}
$$

where $N_{L(B e)}$ is the density of the lithiumlike or berylliumlike charge state, $A_{r}^{f f}$ is the radiative transition probability for the transition in question, and $A_{a}^{x}$ is the autoionization probability to some final state $i$. The excitation rate coefficients $C$ for the lithiumlike and berylliumlike ions were obtained by the same methods as were the rate coefficients for the heliumlike ions, while the autoionization rates were obtained from a factorizationinterpolation technique using a single consistent potential for the bound and continuum orbitals. ${ }^{9}$ The excitation rate coefficients and transition probabilities for Fe XXIV and $\mathrm{Fe}$ XXIII are also listed in Table I.

The emissivities of the lithiumlike dielectronic satellites of the $\mathrm{K} \beta$ lines can be represented by

$$
\varepsilon_{d}=N_{e} N_{H_{e}} F_{1}^{*}\left(T_{e}\right) F_{2}^{*}(s)
$$

where the factor

$$
F_{1}^{*}\left(T_{e}\right)=\frac{1}{2}\left[\frac{2 \pi \mathrm{h}}{m k T_{e}}\right]^{1 / 2} \exp \left(-E_{e} / k T_{e}\right)
$$

depends only on the electron temperature, and

$$
F_{2}(s)=\frac{g_{i}}{s_{i}} \frac{A_{r}^{s f} A_{a}^{s i}}{\sum_{i} A_{a}^{s i}+\sum_{f} A_{r}^{s i}}
$$


is the line strength. Here $g_{S}$ and $g_{i}$ are the statistical weights of the autoionizing states and the ground states, respectively, and $E_{S}$ is the energy of the satellite level above that of the heliumlike ground state. The emissivities of the berylliumlike dielectronic satellite lines are given by an expression similar to (4) except that $N_{H_{e}}$ is replaced by $N_{L}$. The intensity factors $\mathrm{F}_{2}(\mathrm{~s})$ for the strong lithiumlike and berylliumlike dielectronic satellites calculated with the HULLAC package are listed in Tables II and III, respectively.

\section{Experimental Results.}

The spectra were obtained from five nearly identical ohmically heated TFTR discharges with the following parameters: The plasma current and the toroidal magnetic field were $\mathrm{I}_{\mathrm{p}}=1.4 \mathrm{MA}$ and $\mathrm{BT}=3.2 \mathrm{~T}$, and the plasma major and minor radii were $\mathrm{R}=2.48 \mathrm{~m}$ and $\mathrm{a}=0.80 \mathrm{~m}$. These discharges were in steady-state conditions during the period from 1.5 to $4.5 \mathrm{~s}$ and had a peak electron temperature of $2.7 \mathrm{keV}$ and a peak electron density of 4.3 $x 10^{13} \mathrm{~cm}^{-3}$. Figure 1 shows the time evolution of the electron temperature $T_{e}$ and electron density $\mathrm{Ne}_{\mathrm{e}}$ for the TFTR discharge number 28931, which is typical of the discharges used in this experiment. The electron temperature and density data were obtained from electron cyclotron measurements and laser interferometry. Iron was injected into the plasma at $2.7 \mathrm{~s}$ by a laser blow-off technique. The injection led to a substantial increase $(30 \%)$ of the total radiated power, but did not affect the central electron temperature and electron density, see Fig. 1.

The spectral data were recorded with the TFTR horizontal and vertical curved crystal spectrometers. 10,11 The horizontal spectrometer was used to measure the composite spectra of the NiXXVII $\mathrm{K} \alpha$ and the FeXXV K $\beta$ radiation. This spectrometer permits observation of spectral features in the wavelength range 1.57 to $1.62 \stackrel{\circ}{A}$, with a spectral resolving power of $\lambda / \Delta \lambda=7500$. The vertical spectrometer was used for simultaneous observation of the FeXXV K $\alpha$ spectrum near $1.85 \stackrel{\circ}{A}$. Both spectrometers recorded 128 spectra from a discharge with a time resolution of $10 \mathrm{~ms}$ per spectrum, starting at $2.5 \mathrm{~s}$.

Figure 2 shows the time history of the FeXXV $\mathrm{K} \alpha$ and $\mathrm{K} \beta$ line intensities. These line intensities reach a maximum at $2.770 \mathrm{~s}$, i.e. $70 \mathrm{~ms}$ after the injection of iron. The intensities then decay exponentially with an e-folding time of $300 \mathrm{~ms}$, which is a measure of the particle confinement time. A more detailed understanding of these data requires 
plasma modeling calculations, e. g. with the Multi-Ion Species Transport (MIST) cude, 12 which takes into consideration the processes of ionization and recombination as well as ion transport due to diffusion and convection.

Figure 3 presents composite satellite spectra of the iron $\mathrm{K} \beta$ and nickel $\mathrm{K} \alpha$ lines from different time periods: (a) the period from 2.5 to $2.7 \mathrm{~s}$ before the injection of iron, and (b) the period from 2.75 to $2.88 \mathrm{~s}$ after injection, when the radiation from the injected iron is greater than $50 \%$ of its maximum value (see Fig. 2). The satellite spectrum of the NiXXVII $\mathrm{K} \alpha$ line has been described earlier by Hsuan et al. ${ }^{1}$ and by Bitter $\underline{\mathrm{et}}$ al. ${ }^{4}$ The dominant features of the FeXXV K $\beta$ spectrum, the $1 \mathrm{~s}^{2}{ }^{1} \mathrm{~S}_{0}-1 \mathrm{~s} 3 \mathrm{p}^{1} \mathrm{P}_{1}$ and $1 \mathrm{~s}^{2}{ }^{1} \mathrm{~S}_{0}$ $1 \mathrm{~s} 3 \mathrm{p}{ }^{3} \mathrm{P} 1$ transitions, are on the short wavelength side of the NiXXVI $\mathrm{K} \alpha$ line between channels 140 and 160. It is evident from Figs. 3 (a) and (b) that the iron $\mathrm{K} \beta$ spectrum is very weak compared to the nickel spectrum under normal operating conditions in TFTR, but that it is enhanced by an order of magnitude following the iron injection. The second spectrum, Fig. 3(0), also shows some $\mathrm{K} \beta$ satellite lines in the neighborhood of the nickel $\mathrm{K} \alpha$ line $\mathrm{w}$ and in the wavelength range of the nickel features $\mathbf{x}, \mathbf{s}$ and $\mathrm{t}$, see Gabriel's notation. 13 The : features are not apparent in Fig. 3(a). The nickel resonance line $w$, the dielectronic satedlite line $j$ and the combined lines $q$ and $y$, as well as $l, \beta$ and $z$ (see Gabriel's notation ${ }^{13}$ ) are not distorted by the iron lines, even during strong iron injection.

Since the electron temperature $\mathrm{T}_{e}$ and the electron density $\mathrm{N}_{e}$ were not affected by the iron injection, the nickel spectrum of Fig. 3(a) can be normalized and subtracted from the composite nickel-iron spectrum of Fig. 3(b). The experimental iron $\mathrm{K} \beta$ spectrum obtained in this way is shown in Fig. 4(a). The main features of the observed spectrum include the $K \beta_{1}$ and $K / \beta_{2}$ lines (labeled 1 and 2 ) and the more prominent satellite transitions 3 through 9 which are identified in Table 4 . In order to determine wavelengths of the observed spectrum accurately, the central channel numbers for the prominent peaks have been obtained by a least squares fit of Voigt profiles to the experimental data. These central channel numbers have then been converted to wavelengths using the equation

$$
\lambda=2 d \sin \left(\theta_{0}+\Delta \theta\right)
$$

where $2 \mathrm{~d}=2.028 \AA$ is the $2 \mathrm{~d}$-spacing of the quartz crystal (cut: 2243 ) and $\Delta \theta$ (deg) $=$ $9.6880 \times 10^{-3}\left(\mathrm{~N}-\mathrm{N}_{0}\right)$ is the dispersion of the instrument. $\mathrm{N}_{0}$ and $\theta_{0}$ are the channel number and the Bragg angle for the nickel line $w$. Since the spectrometer has no 
absolute wavelength calibration, the theoretical wavelength value of $1.5884 \AA$ for the nickel $w$ line from Safronova's calculations ${ }^{14}$ is used as a reference value, i. e. we assigned $\lambda_{0}^{\text {theor }}=1.5884=2 d \sin \left(\theta_{0}\right)$ to channel number $N_{0}$. The experimental wavelengths of the prominent featlires are shown in Table 4 together with the theoretical wavelengths of the present calculations, see Tables II and III, and those from the calculations by Safronova, ${ }^{14}$ Chen 15 and Nilsen. ${ }^{16}$ Safronova uses the $1 / \mathrm{Z}$ expansion perturbation technique, with relativistic corrections taken into account within the framework of the Breit operator. Chen 15 computes the relevant atomic data relativistically in intermediate coupling using configuration interaction in the multiconfiguration Dirac-Fock model (MCDF); a generalized Breit interaction and QED corrections were also taken into account. The third set of calculations by Nilsen uses MCDF for bound states and distorted-wave Dirac continuum states for electrons.

The different sets of theoretical wavelengths listed in Table 4 are in good general agreement with the experimental wavelengths, given that these wavelengths can be shifted by a constant amount due to the fact that the spectrometer is not absolutely calibrated. The wavelengths of Safronova's calculations seem to be more consistent with the observed data; the wavelengths from our calculations tend to be smaller than the observed values by about $0.3 \mathrm{~m} \stackrel{\circ}{A}$, while those from Chen and Nilsen tend to be 0.2 and $0.7 \mathrm{~m} \stackrel{\circ}{A}$, respectively, larger than the observed data.

Figure 4(b) shows a synthetic FeXXV K $\beta$ spectrum constructed from the present theoretical data. The additional parameters, i. e. the electron and ion temperatures, $\mathrm{T}_{e}$ and $T_{i}$, as well as the relative densities, $\mathrm{NHe}_{\mathrm{He}} \mathrm{NLi}$ and $\mathrm{NBe}$, of the heliumlike, lithiumlike, and berylliumlike charge states of iron, have been derived from the iron $\mathrm{K} \alpha$ spectrum which was observed with the vertical TFTR spectrometer. The synthetic spectrum shown in Fig. 4(b) was obtained using $\mathrm{Te}=2.7 \mathrm{keV}, \mathrm{Ti}=3.0 \mathrm{keV}$, and with $\mathrm{N}_{\mathrm{He}}, \mathrm{NLi}_{\mathrm{Li}}$ and $\mathrm{N}_{\mathrm{Be}}$ in the ratio of $1.0: 0.55: 0.11$.

\section{Conclusions.}

The Fe XXV K $\beta$ spectrum has been obtained from TFTR discharges and found to be in good agreement with a synthetic spectrum constructed from new thcoretical predictions. Since the iron $\mathrm{K} \beta$ spectrum was partially blended with the Ni XXVII $\mathrm{K} \alpha$ spectrum, it was necessary to enhance the intensity of the $\mathrm{K} \beta$ radiation by the injection of iron into 
the plasma. A total of nine features in the Fe XXV K $\beta$ spectrum have been identified. The relative intensities depend on the electron temperature and charge state balance, which suggests their future use for plasma diagnostics.

Experimental wavelengths of the FeXXV K $\beta$ spectrum have been determined relative to the Ni XXVII $\mathrm{K} \alpha$ resonance line. The satellite lines of the iron $\mathrm{K} \beta$ spectrum do not interfere with the Ni XXVII $\mathrm{K} \alpha$ resonance line. This is important for both TFTR and Tore Supra plasmas where iron and nickel are simultaneously present as impurities and where the Ni XXVII $\mathrm{K} \alpha$ line is used for ion temperature measurements.

Acknowledgments. We deeply appreciate the fruitful discussions with Professor U. I. Safronova and would like to thank ier for making her most recent wavelength calculations for the FeXXV $\mathrm{K} \beta$ s ccis m available to us. We also gratefully acknowledge the continuing support of D. Meade, R. J. Hawryluk and K. M. Young, the technical assistance of J. Gorman, R. Such and the TFTR operating crew, and software support by N. Schechtman. This work was supported by the U.S. Department of Energy, Contract No. DE-AC02-76-CHO-3073 and Contract No. W-7405-Eng-48. 


\section{References}

(1) H. Hsuan, M. Bitter, K. W. Hill, S. von Goeler, B. Grek, D. Johnson, L. C. Johnson, S. Sesnic, C. P. Bhalla, K. B. Karim, F. Bely-Dubau and P. Faucher, Phys. Rev. A 35 4280(1987).

(2) F. Bombarda, R. Giannela, E. Källne, G. J. Tallents, F. Bely-Dubau, P. Faucher, M. Cornille, J. Dubau and A. H. Gabriel, Phys. Rev. A 37, 504(1988); and H. Hsuan, M. Bitter, J. E. Rice, K. W. Hill, L. Johnson, S. L. Liew, S. D. Scott, and S. von Goeler, Rev. Sci. Instrum. 59, 2127(1988).

(3) F. Bombarda, R. Giannella, E. Källne, G. J. Tallents, J. Quant. Spectrosc. Radiat. Transf. 41,323 (1989).

(4) M. Bitter, H. Hsuan, V. Decaux, B. Grek, K. W. Hill, R. Hulse, L. A. Kruegel, D. Johnson, S. von Goeler and M. Zarnstoff, Phys. Rev. A 44, 1796(1991).

(5) In 1987 the Inconel bellows cover plates were covered with graphite tiles, so that the concentration of nickel was very much reduced and iron became the dominant metal impurity in TFTR discharges. Line radiation from nickel could then no longer be used for ion temperature measurements and the spectrometer was realigned for the observation of the FeXXV $\mathrm{K} \alpha$ line.

(6) F. Bely-Dubau, A. H. Gabriel and S. Volonte, Mon. Not. R. Astr. Soc. 186,405(1979); and M. Bitter, S. von Goeler, K. W. Hill, R. Horton, D. Johnson, W. Roney, N. Sauthoff, E. Silver and W. Stodiek, Phys. Rev. Lett. 47. 921(1981).

(7) M. Klapisch, Comput. Phys. Commun. 2, 239(1971); and M. Klapisch, J. L. Schwob, B. S. Fraenkel, and J. Oreg, J. Opt. Soc. Am. 61, 148(1977).

A. Bar-Shalom, M. Klapisch, and J. Oreg, Phys. Rev. A $\underline{38}$, 1773(1988).

(9)

J. Oreg, A. Bar-Shalom, W. H. Goldstein, and M. Klapisch, Phys. Rev. A 44, 1750(1991). 
(10) M. Bitter, K. W. Hill, S. Cohen, S. von Goeler, H. Hsuan, L. C. Johnson, R. Raftopoulos, M. Reale, N. Schechtman, F. Spinos, J. Timberlake, N. Young and K. M. Young, Rev. Sci. Instrum. 57 2145(1986).

(11) K. W. Hill, M. Bitter, M. Tavernier, M. Diesso, S. von Goeler, G. Johnson, L. C. Johnson, N.. Sauthoff, N. Schechtman, S. Sesnic, F. Tenney and K. M. Young, Rev. Sci. Instrum. 56, 1165(1985).

(12) R. A. Hulse, Nucl. Technol. Fusion 3, 259 (1983).

(13) A. H. Gabriel, Mon. Not. R. Astr. Soc. 160 79(1972).

(14) U. I. Safronova, personal communication, 1992.

(15) M. H. Chen, Atomic Data and Nuclear Data Tables 34, 301(1986).

(16) J. Nilsen, Atomic Data and Nuclear Data Tables 37,191(1987) 
Table I: Excitation rate coefficients, for direct electron impact excitation from the ground states of (a) FeXXV, FeXXI, and (b) FeXXIII at electron temperatures between 1.2 and $4.0 \mathrm{keV}$. Also listed are the autoinization probabilities $A_{a}^{s i}$, the radiative transition probabilities $A_{r}$, and the branching ratios defined as $\beta_{r}=\frac{A_{r}^{s f}}{\sum_{f} A_{r}^{s f}+\sum_{i} A_{a}^{s i}}$. The numbers in square brackets are powers of ten.

Table II: Intensity factors for the lithiumlike dielectronic satellite lines of the iron $\mathrm{K} \beta$ lines; only lines with line factors larger than $1 \%$ of the strongest satellite are listed. Numbers in square brackets signify powers of 10 .

Table III: Intensity factors for the berylliumlike satellites of the iron $\mathrm{K} \beta$ lines; only lines with $F_{2}(s) \geq 2.0 \times 10^{12} \mathrm{~s}^{-1}$ are included. Numbers in square brackets signify powers of 10 .

Table IV: Experimental wavelengths and theoretical predictions for the lines in the iron $\mathrm{K} \beta$ spectrum; peaks are numbered as in Fig 6. 


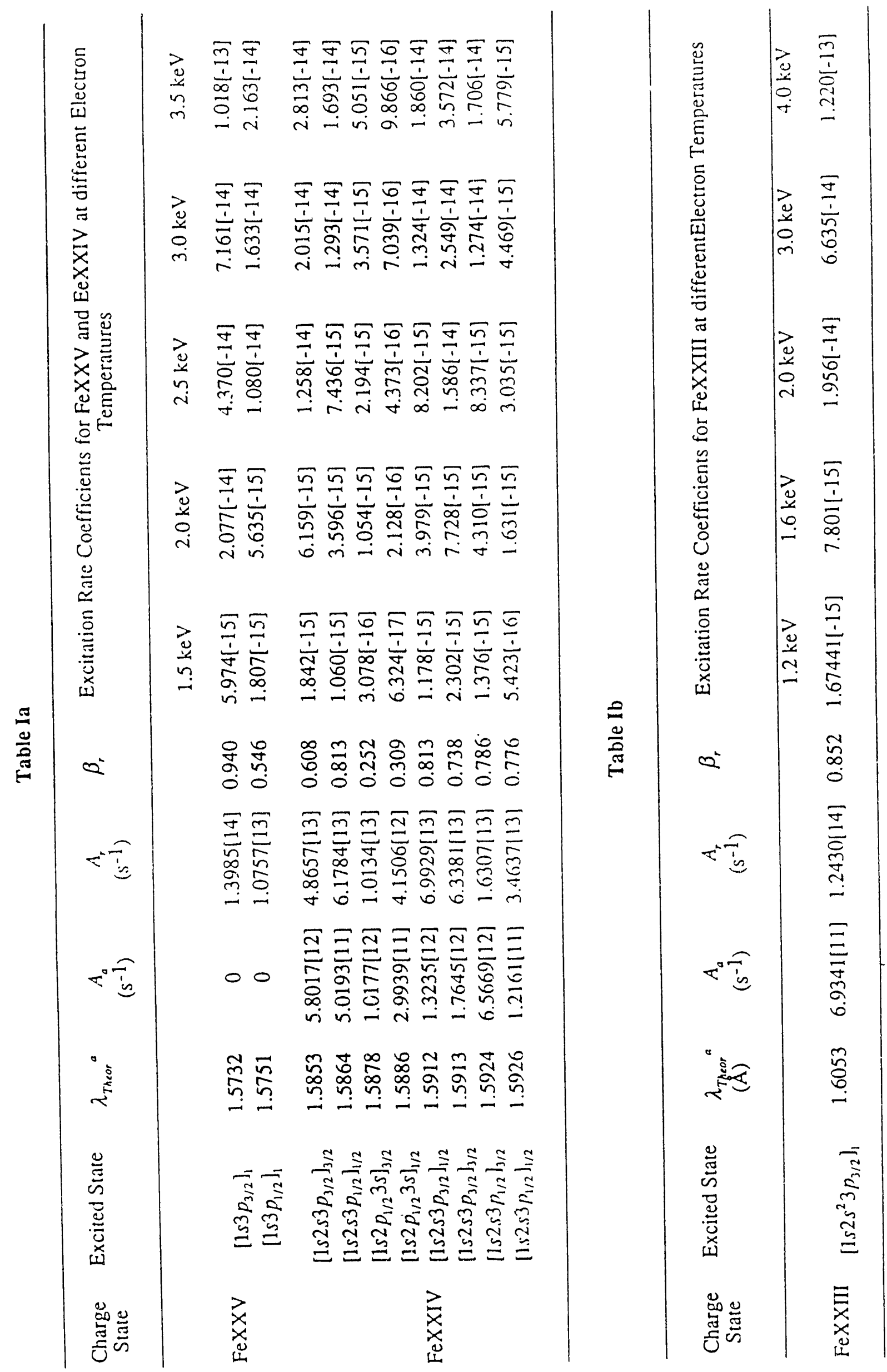




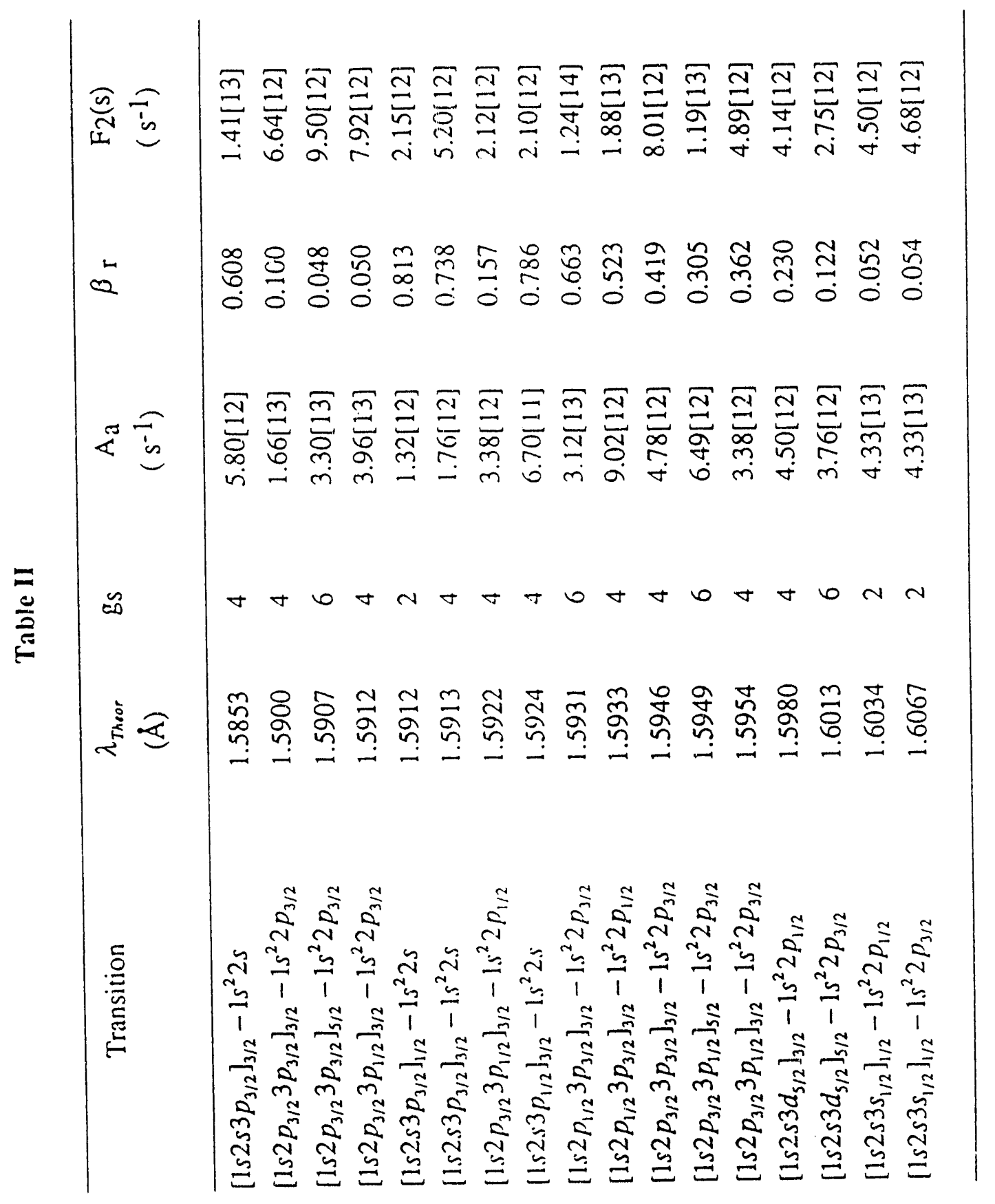




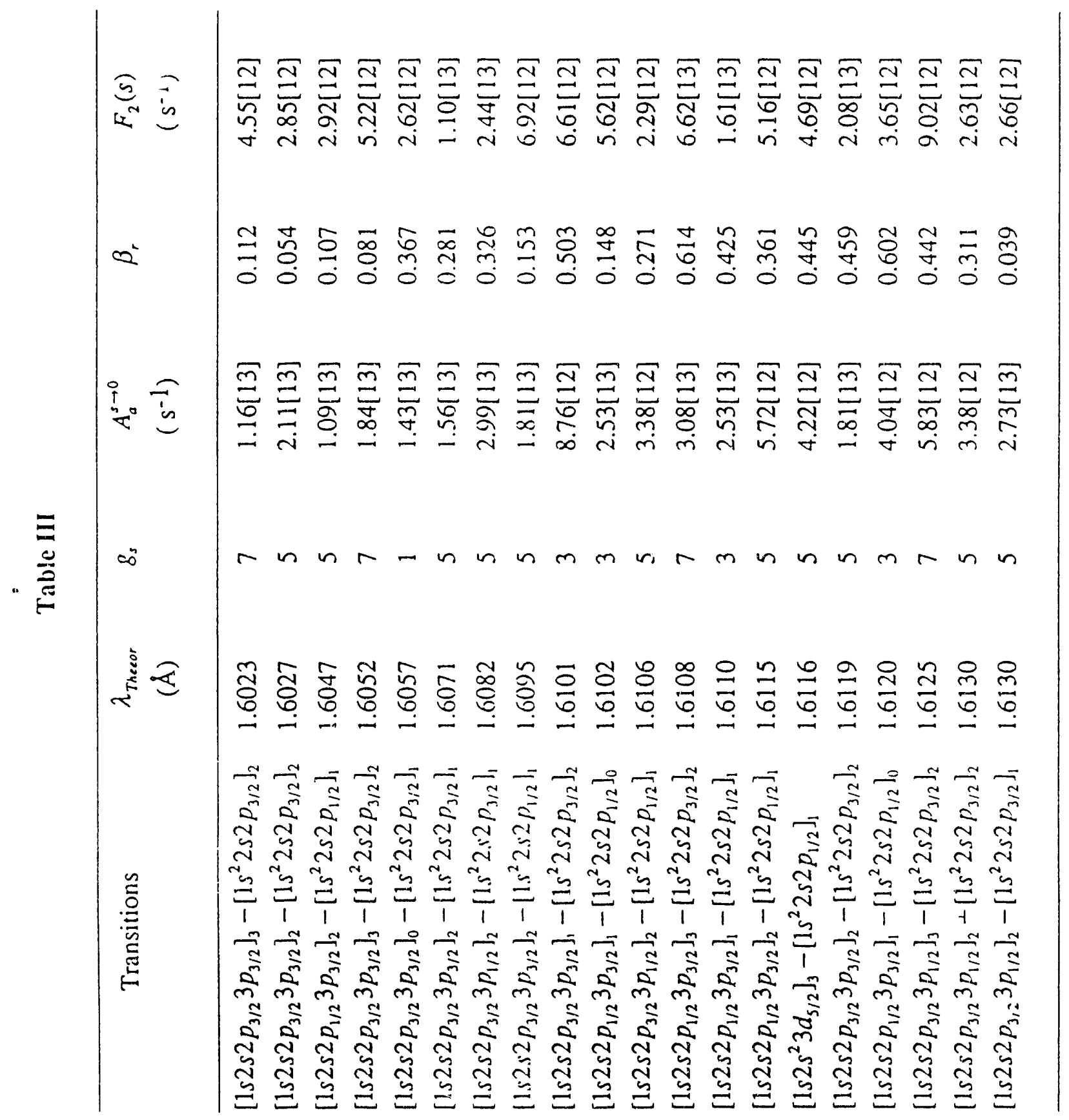




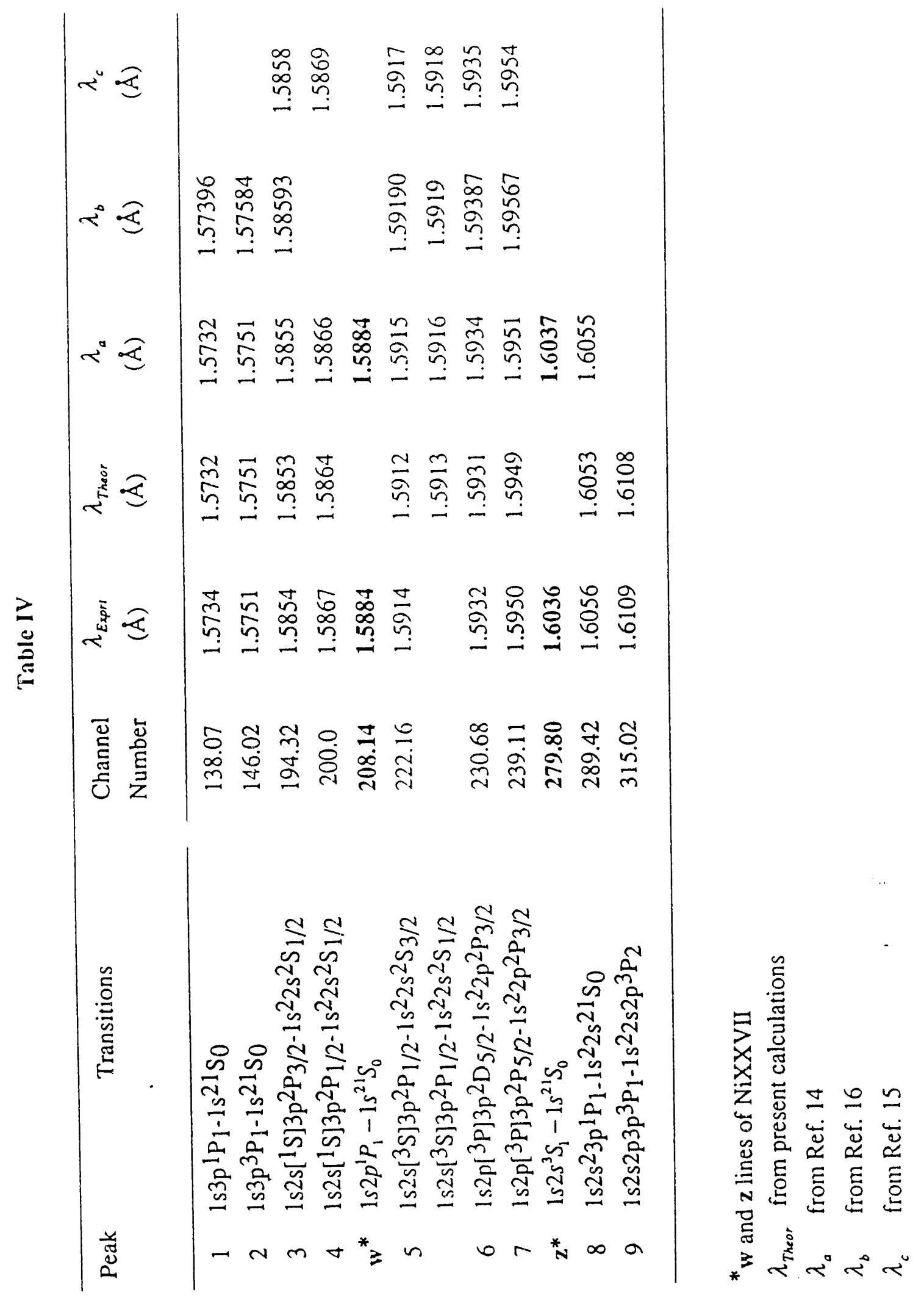




\section{Figure Captions}

Figure 1: Electron temperature and electron density as functions of time for TFTR shot 28931. The data were obtained from measurements of the electron cyclotron emission and laser interferometry. Iron was injected at $2.7 \mathrm{~s}$ by a laser ablation technique.

Figure 2: Time history of (a) the $\mathrm{Fe} \mathrm{K} \beta$ and (b) the $\mathrm{Fe} \mathrm{K} \alpha$ line intensities.

Figure 3: Satellite spectra of Ni XXVII $\mathrm{K} \alpha$ and Fe XXV K $\beta$ (a) before and (b) after iron injection. The data have been accumulated from five nearly identical TFTR ohmic shots during the periods $2.5-2.7 \mathrm{~s}$ for Fig. 3 (a) and $2.75-2.88$ $\mathrm{s}$ for Fig. 3 (b). The features of the Ni XXVII $\mathrm{K} \alpha$ satellite spectrum have been identified using Gabriel's notation. 13 The Fe XXV $\mathrm{K} \beta$ features are significantly enhanced in the spectrum (b) which was recorded after iron injection.

Figure 4: (a) Experimental iron $\mathrm{K} \beta$ spectrum obtained by subtracting a normalized spectrum of Fig. 3 (a) from the spectrum shown in Fig. 3 (b). (b) Synthetic iron $\mathrm{K} \beta$ spectra constructed from present theoretical data for the measured electron and ion temperatures of $\mathrm{T}_{\mathrm{e}}=2.7 \mathrm{keV}$ and $\mathrm{T}_{\mathrm{i}}=2.35 \mathrm{keV}$. The shaded area represents the satellite contributions from collisional inner-shell excitation. The solid line represents the entire spectrum including contributions from dielectronic recombination. 


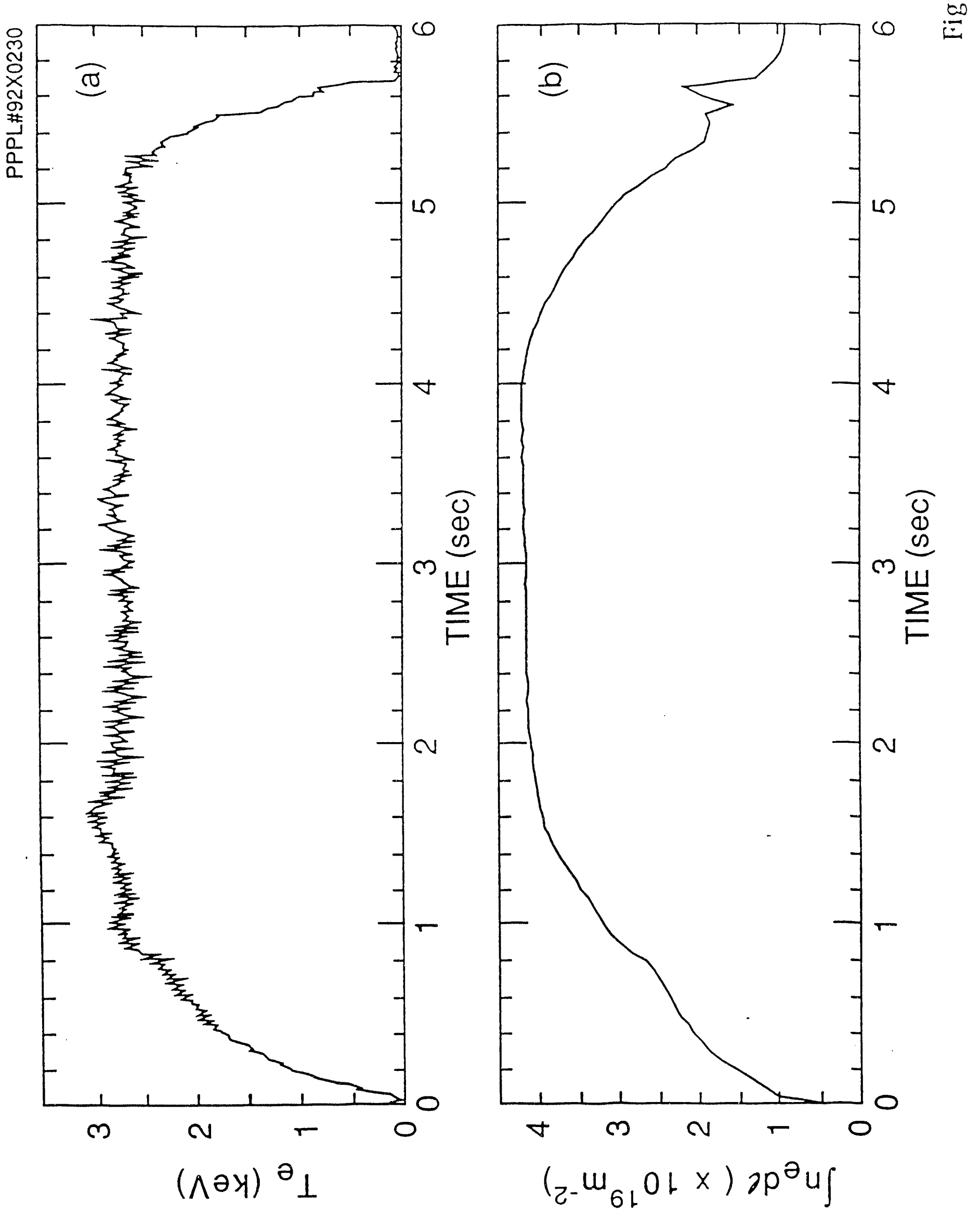




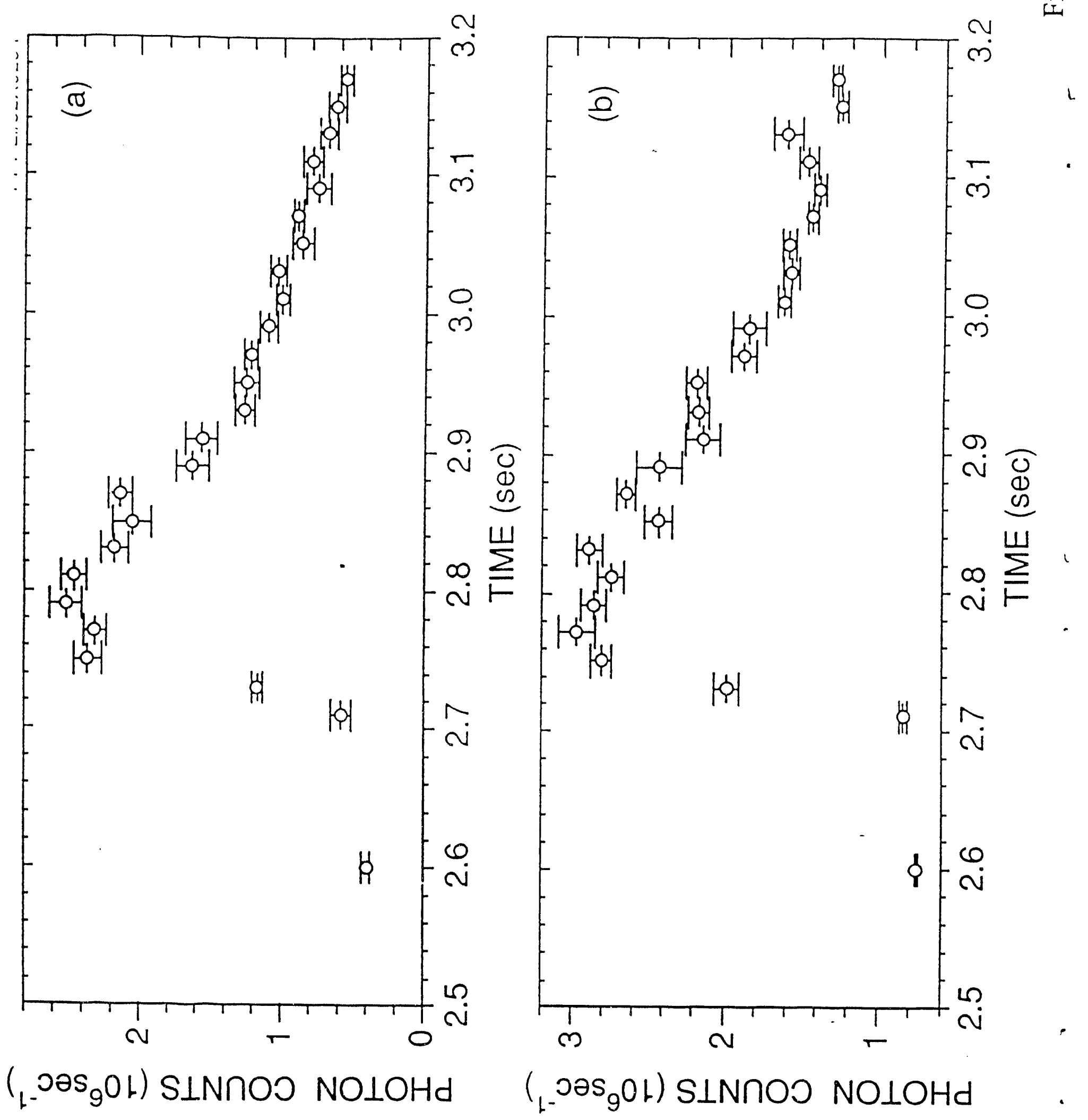




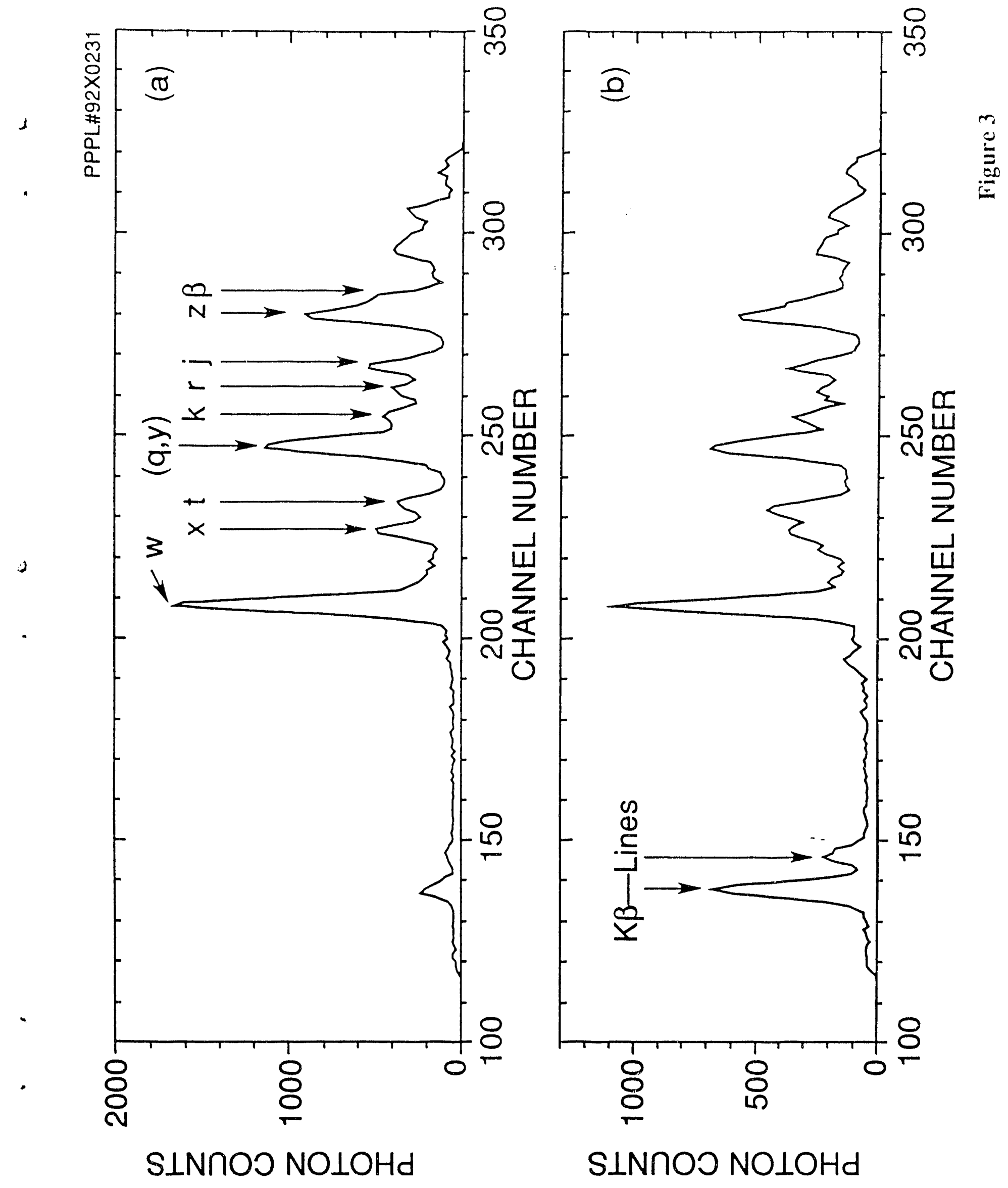




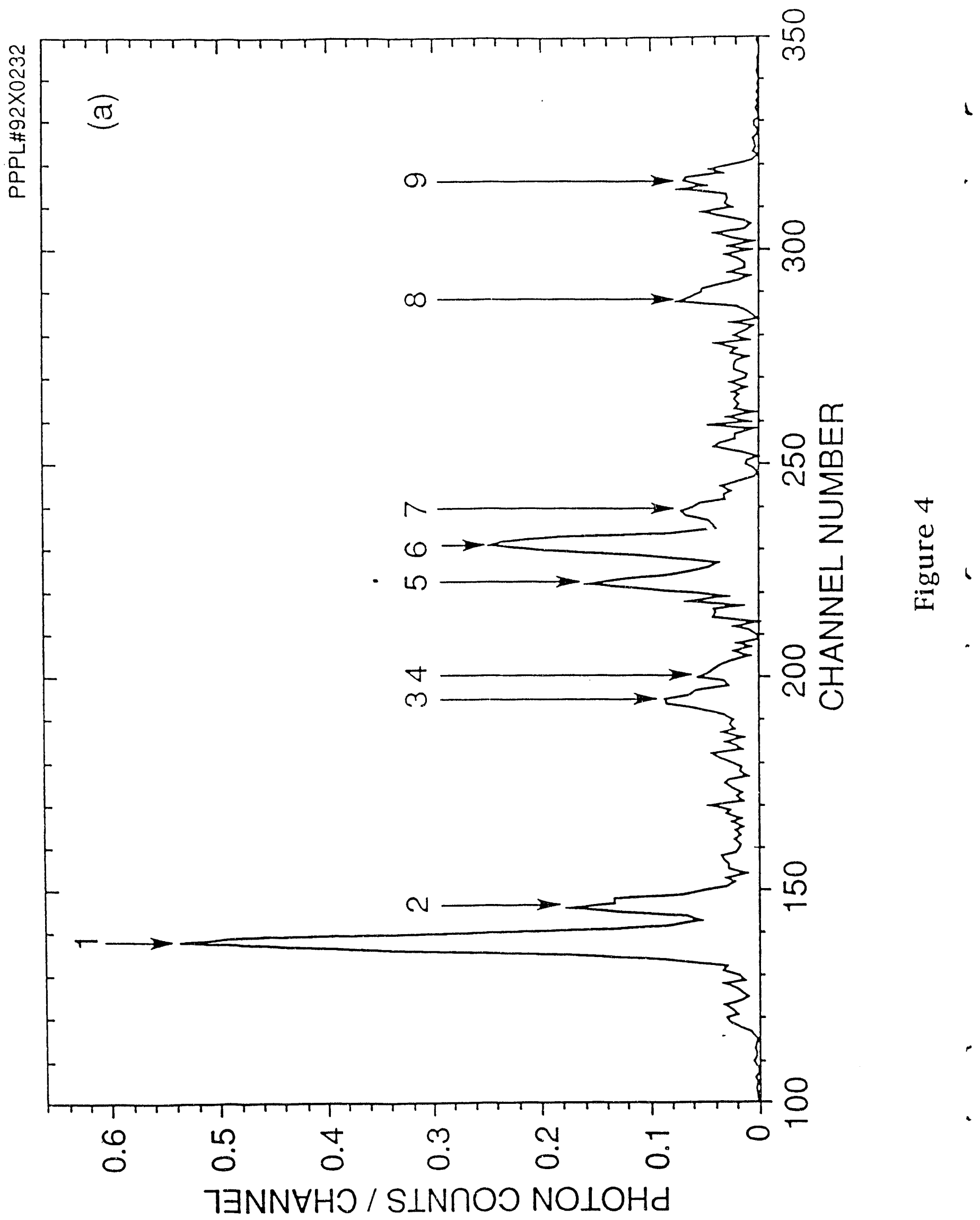




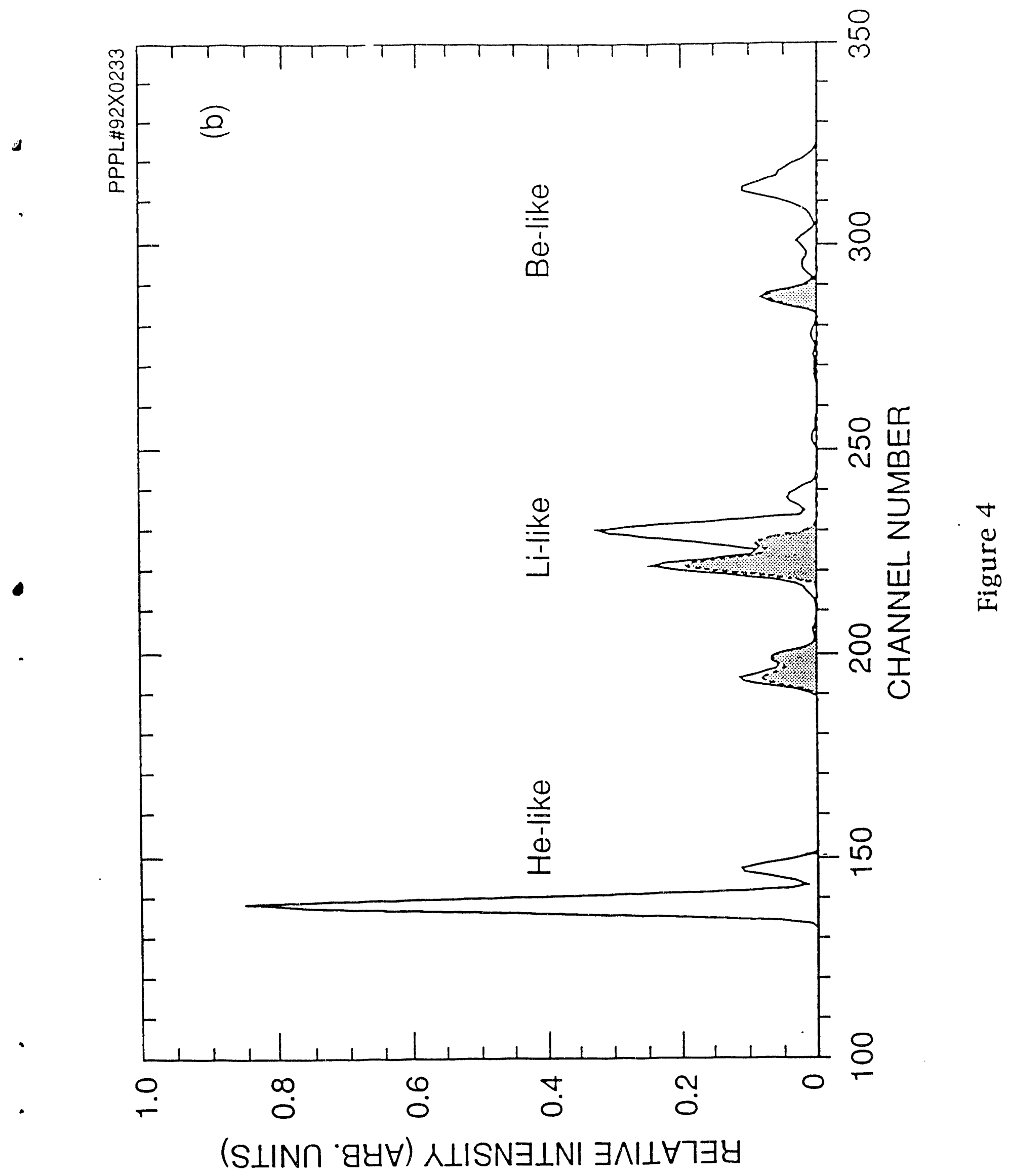


Dr. F. Psoloni, Univ. of Woltongong. AUSTRALIA

Prof. M.H. Bronnan, Univ. of Sydney, AUSTRALIA

Plasma Reseanch Lab., Austration Nal. Univ., AUSTRALIA

Prof. I.A. Jones, Flinders Univ, AUSTRALIA

Prot. F. Cap, Inst. for Theoretical Physics, AUSTRIA

Prot. M. Hoindier, Inztiut tor Theoreliscte Physik, AUSTRIA

Prot. M. Gooseens, Astronomisch instituUt, BELGIUM

Ecole Royedo Malitrine, Lat. do Phy. Plaemas, BELGIUM

Commicsion-Europeen, DG. XII-Fusion Prog., BELGIUM

Prof. R. Bouciqus, Rijksunivercibit Gont, BELGIUM

Dr. P.H. Sekenaka, Instituto Fitica, BRUZIL

Instituto Meciond Do Pasquisas Especieis-INPE, BRAZIL

Documents Office, Alomic Enorgy of Cenada Ld., CANADA

Dr. M.P. Bectyneki, MPB Technotogies, Inc., CANADA

Dr. H.M. Skarsoard, Univ. of Sackakchowen, CANADA

Prol. J. Toichmam, Univ. of Montroed, CANADA

Prot. S.R. Sreenivasen, Univ. of Colgary, CANADA

Prof. T.W. Johnston, INRS-Energio. CANADA

Dr. R. Botton, Contro canadien de tusion megnetique, CANADA

Dr. C.R. James, Univ. of Aborta, CANADA

Dr. P. Lukde, Komonsketho Univerezita, CZECHOSLOVAKIA

The Librarian, Culham Laboralory, ENGLANO

Librery, R61, Authortord Appleton Laboratory, ENGLAND

Mrs. S.A. Huxctinson, JET Librery. ENGLAND

Dr. S.C. Sherme, Univ. of South Pacific, FIJI ISLANDS

P. Mahonen, Univ. of Helsinki, FINLAND

Prof. M.N. Buseac, Ecols Polytechnique, FRANCE

C. Moutror, Lob. do Phÿ̈. jue des Milioux boniser, FRANCE

J. Radot. CENCADARACHE - Bat 506, FRANCE

Prof. E. Economou, Univ. of Crete, GREECE

A6. C. Rinni. Univ. of loamina, GREECE

Dr. T. MUA, Academy Bibliographic Ser., HONG KONG

Proprint Librery. Hungarian Acadomy of Sci., HUNGARY

Dr. B. DasGupta, Saha inst of Nuctoer Ptysics, INDIA

Dr. P. Kaw, Inst. for Plasma Rosearch, INDIA

Dr. P. Rosenau, lerwed Inst of Technology, ISPAEL

Librevian, Intomational Contor for Thoo Phycics, ITALY

Miss C. De Palo, Associezione EURATOMENEA, ITALY

Dr. G. Grosso, Istiuto di Fiesica ded Plasma, ITALY

Prof. G. Rostangni, Istituto Gas lonizzati Ded Cnr, ITALY

Dr. H. Yamato, Tochiba Res a Dever Center, JAPAN
Prof. I. Kawakami, Hirostima Univ., JAPAN

Prof. K. Nichikawe, Hiroshima Univ., JAPAN

Director, Jepen Atomic Enorgy Research inst, JAPAN

Prof. S. Itoh, Kyushu Univ., JAPAN

Research into. Cr., National instit. for Fusion Science, JAPAN

Prof. S. Tenaka, Kyoto Univ., JAPAN

Library, Kyoto Univ., JAPAN

Prot. N. Inowe, Univ. of Tokyo, LAPAN

Secretary, Plasma Section, Electrolechnical Lab., JAPAN

S. Mori, Technical Advieor, LAERI, JAPAN

Dr. O. Miterai, Kumamoso Inst of Technology. JAPAN

J. Hyeon-Sook, Korea Atomic Energy Research inst, KOREA

D.1. Choi, Tha Korea Adv. Inst of Sa. \& Tech., KOREA

Prof. B.S. Liby, Univ. of Waikato, NEW ZEALAND

Inst of Phyics, Chimese Acad Sa PEOPLE'S REP. OF CHINA

Librey, Inst of Plasma Physics, PEOPLE'S REP. OF CHINA

Tsinghun Univ. Library, PEOPLE'S REPUBLIC OF CHINA

Z. Li, S.W. Inst Physica, PEOPLE'S REPUBUC OF CHINA

Prof. J.A.C. Cebral, Instituto Sucrinor Tecnico, PORTUGAL

Dr. O. Porne, Al I Cuza Univ., Romania

Dr. J. do Villiars, Fusion Studies, AEC, S. AFRICA

Prot. M.A. Hemberg, Univ. of Nami, S. AFRICA

Prof. D.E. Kim, Pohang inst. of Sa. Tech., SO. KOAEA

Prot. C.I.E.M.A.T, Fusion Division Library, SFAIN

Dr. L Sienfio, Univ. of UMEA, SWEDEN

Libray. Royed inst. of Technology, SWEDEN

Prof. H. Withaimeon, Chelmors Univ. of Tech., SWEDEN

Contre Phys. Des Plasmas, Ecole Polytech, SWITZERLAND

Bibliothoek, Inst. Voor Plasma-Fyeica, THE NETHERLANDS

Asst Prot. Dr. S. Cokir, Midcte Eest Tech. Univ., TUAKEY

Dr. V.A. Gusthith,Sai. Res. Inst. Electrophys.I Apparatus, USSR

D. D.D. Ayutov, Siborian Brench of Acadomy of Sa., USSR

Or. G.A. Eliseov, I.V. Kurchatov Inst, USSA

Librerien, The Ukr.SSA Acedemy of Scionces, USSR

Dr. LM. Kovrizhmykh, Inst. of Genorel Physias, USSR

Komforsctunganaloge GmbH, Zontrabibliothek, W. GERMANY

Bibliothok, Inst. FOr Ptasmatorechung, W. GERMANY

Prot. K. Schindler, Rutr-Universith Buchum, W. GERMANY

D. F. Wagner, (ASDEX), Max-Planck-Institut, W. GERMANY

Librarian, Max-Plenck-Institurt, W. GERMANY

Prot. R.K. Janew, Inst of Physics, YUGOSLAVIA 